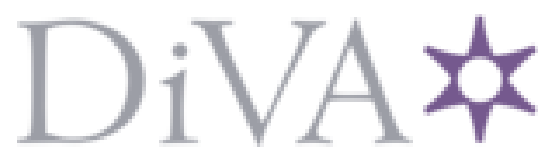

http://www.diva-portal.org

\title{
Postprint
}

This is the accepted version of a paper published in International journal of machine tools \& manufacture. This paper has been peer-reviewed but does not include the final publisher proofcorrections or journal pagination.

Citation for the original published paper (version of record):

Ng, A., Adolfsson, J., Sundberg, M., De Vin, L. (2008)

Virtual Manufacturing for Press Line Monitoring and Diagnostics.

International journal of machine tools \& manufacture, 35: 565-575

Access to the published version may require subscription.

N.B. When citing this work, cite the original published paper.

Permanent link to this version:

http://urn.kb.se/resolve?urn=urn:nbn:se:kau:diva-30131 



\section{Virtual Manufacturing for Press Line Monitoring and Diagnostics}

\section{Amos H.C. Ng, Josef Adolfsson, Martin Sundberg, Leo J. De Vin ${ }^{1}$}

University of Skövde, Sweden

Box 408, 54128 Skövde, Sweden.

amos.ng@his.se josef.adolfsson@his.se martin.sundberg@asko.se leo.devin@his.se

\section{ABSTRACT}

Virtual manufacturing, or manufacturing simulation, can be divided into three domains: Product domain, process domain, and resource domain. This paper focuses on the use of virtual manufacturing for press line monitoring and diagnostics. It contains an introduction to virtual manufacturing, divided into a general part on modelling \& simulation, verification, validation $\&$ acceptance, and the division into the three domains, as well as a specific part on the use of simulation in these domains for sheet metal products, processes and processing equipment. The main software tools discussed in this paper are discrete event simulation and computer aided robotics; the designed and implemented machine service support system is an example of advanced use of 3-D graphical simulation in the resource domain. This system offers remote on-line monitoring and diagnostics functions as well as media player type functions such as replay that allow a service \& maintenance expert to analyse disturbances that occur at remote locations. A key feature of the system is 3-D graphical simulation with I/O synchronisation. This type of system is particularly useful for system integrators and machine builders that install press lines and press cells world-wide and need to guarantee a high level of availability of the installed machinery.

KEYWORDS: Virtual Manufacturing, Press Lines, Service \& Maintenance

\footnotetext{
${ }^{1}$ Corresponding Author, telephone +46 500 448504, fax +46 500448599
} 


\section{INTRODUCTION}

Key factors to remain competitive in the sheet metal manufacturing business are the effective and efficient operation of installed manufacturing systems, as well as the ability to reconfigure these systems quickly and readily in the case of for instance new product introduction. Sheet metal manufacturing systems usually consist of a number of people, machines and handling devices. These systems are sufficiently complex and sophisticated that (re)design, operational production planning (scheduling) and machine service \& maintenance are intricate specialist tasks. As a result, these tasks increasingly require adequate decision support. It is believed that virtual manufacturing, or manufacturing simulation, can provide such decision support for manufacturing system life cycle management [1].

Various authors stress the need for companies in the sheet metal manufacturing business to form alliances to provide complete solutions on an agile basis in a global market [2-4]. The ARMMS consortium has identified a number of enabling key technologies for achieving agility, virtual manufacturing being one of these key technologies [5]. Iskanius [3] explains how even manufacturers acting on a local market cannot escape globalisation; not only will other -external- actors try to compete on this local market; local manufacturers are often foreign-owned and compete for investments in their company on a global scale. She indicates that the sheet metal manufacturing business in general still has an imago of being fairly traditional and unspectacular and that this hampers attracting attention and funding from international investors. Eriksson [6] explains more specifically how manufacturing companies can benefit from adopting innovations such as virtual manufacturing and discusses various innovation adoption strategies. 
Virtual manufacturing is a collective name for a variety of modelling and simulation tools, techniques and applications. It encompasses for instance simulation for product development, for production system development (which, from a machine builder perspective, is similar to product development), and simulation as a support for other life-cycle phases such as operational planning [7, 8], service \& maintenance [9] and decommissioning [10]. This paper gives a general introduction to the use of virtual manufacturing, in particular simulation for sheet metal product realisation processes, in the form of a brief literature review (Section 2). After this, an example of advanced application of virtual manufacturing is given in Section 3. This application forms the basis for a specific application of virtual manufacturing, namely simulation based service \& maintenance support for press lines (Sections 4 and 5). Service \& maintenance support can be beneficial already within a single production plant; the benefits are even larger when it is used for providing service $\&$ maintenance at remote locations. It assists press line builders to provide their customers with total productivity solutions. Providing such service is often part of a service \& maintenance agreement as negotiated by the customer; it also happens that press lines are installed on the basis of a lease agreement through which the customer leases production capacity rather than the press line itself. Thus, the ability to provide swift and adequate service and maintenance is not only a means to obtain a competitive edge, often it is a contractual obligation.

\section{VIRTUAL MANUFACTURING (VM) FOR SHEET METAL}

\section{APPLICATIONS}

\subsection{Introduction to Modelling \& Simulation}

In this section, a brief overview on Virtual Manufacturing for sheet metal applications is presented. This serves two purposes. Firstly, it puts the machine service support system 
discussed later on in a broader perspective. Secondly, overviews of VM generally do not focus on sheet metal applications.

\subsubsection{Definitions and Use of Modelling \& Simulation}

There are numerous definitions of simulation. A suitable definition could be:

“Simulation: To represent a (real-world) system by another (computer based) system in order to study the dynamic behaviour or properties of the (real-world) system in a virtual environment”. In more general terms, we can describe simulation as "experimentation with some model of a System of Interest (SoI)". This SoI may be an existing system, a projected system, or a completely imaginary system. The model may be computer based (as we will assume in the remainder of this paper) but this is not a necessity.

\subsubsection{Verification, Validation and Acceptance}

Simulation essentially means experimentation with a model of the SoI (Figure 1). Verification, Validation \& Acceptance (VV\&A) is a process that results in a recommendation regarding the trustworthiness of the model [11-13]. Verification is the VV\&A step that addresses the question whether we built the model right; i.e. is it free of bugs. Validation is the step that deals with the question to which degree the results from simulations with the use of the models can be trusted. Except for perhaps models of simple man-made systems, there can never be a guarantee that a model is correct and valid; all we can do is arrive at a certain level of confidence that the model and the envisaged SoI show behavioural indistinguishability within accepted tolerances. 




[insert about here:] Figure 1: Relationships between System of Interest and

Model [12]

\subsection{Manufacturing Simulation and the three PPR Domains}

Within the context of an integrated approach to product- and production development, it is mandatory to consider products, processes and resources ("PPR domains", also called "PPR hub") concurrently. This division into three domains is also very suitable when discussing different types of simulation or applications of the same modelling \& simulation technique in different domains. It also indicates that there may be many orders of magnitude in time scales or spatial scales, for instance between simulation-in-the-loop for in-process control of sheet welding processes and discrete event simulation of the product flow in a production plant, an issue also highlighted by the NSF Blue Ribbon Panel on Simulation-Based Engineering Science [14].

\subsection{Modelling \& Simulation in the Product Domain}

Many aspects of products may be simulated, but for sheet metal products, mainly physical properties are of interest. Two well-known methods that are commonly used in industry are the finite element (FE) method and multi-body system (MBS) simulation. The importance of product simulation in general is that it facilitates the 
sliding between existing and not yet existing objects, and supports the designer in decision making through the possibility to explore "what if" scenarios [15].

The FE method is a general method to model and simulate the physical behaviour of bodies. FE simulations are often used as a tool for detailing components, but it is also possible to use the FE method in the earlier phases of the design process. There is a trend to study detailed behaviour of complex artefacts with FE simulations assisted by reduced testing [16].

Modelling of the dynamic behaviour of a multi-body system is characterised by a composition of rigid bodies, interconnected by joints, springs, dampers, and actuators. However, especially for sheet metal components, the rigid body assumption is often a too crude approximation. In order to remedy this, many MBS software packages such as ADAMS have capabilities to import condensed FE models [17].

\subsection{Modelling \& Simulation in the Process Domain}

In the process domain, the manufacturing processes are modelled and simulated. Examples of processes are punching, laser cutting, welding, and a variety of bending/forming processes such as air bending, deepdrawing, hydroforming, laser bending. For 3-D forming process, mainly FE modelling and simulation is used, for instance $[18,19]$. Modelling and simulation of brakeforming and more in particular air bending has been the focus of renewed attention during the nineties, but recent articles [20, 21] and industrial projects [22] show that modelling and simulation of these processes still receives ample attention in academia and industry. Models for air bending are often FE models [23, 24] or analytical models [25, 26]. Examples of the application of process models for in-process control can be found in [27, 28]. FE models can be used for studies of sheet metal working processes [29] as well as for 
process related studies such as tool and press brake deflections in bending [30] or tool performance for punching [31].

\subsection{Modelling \& Simulation in the Resource Domain}

In the context of this paper, modelling \& simulation in the resource domain is restricted to 3-D graphical simulation of manufacturing machinery (such as robots) and production lines. The simulation technologies considered are Discrete Event Simulation (DES, sometimes also referred to as "production flow simulation") and Computer Aided Robotics (CAR, sometimes also referred to as "geometry simulation" or "continuous simulation", Figure 2). DES tools are normally used to study the product flow in a manufacturing facility, although their use can be extended to other areas than manufacturing such as healthcare [32]. In DES, the simulation makes a step when an event happens, for instance if a product is finished. DES tools use statistical distributions for processing times, mean time between failures and so on. They are often used to study throughput capacity and throughput times, to identify bottlenecks or to optimise buffer sizes. CAR tools are normally used to study movements of industrial robots and so on, with collision avoidance and off-line programming as important applications. In CAR, the movements are semi-continuous, i.e. proportional to time with very small increments. The CAR model of the cell in Figure 2 shows a press with a materials handling robot that feeds the press with sheets from the de-stacker and handles stamped parts and waste material by placing these onto two different conveyors. A technology related to CAR is ergonomic simulation, which is used for instance for posture analysis in workplace design [33]. 


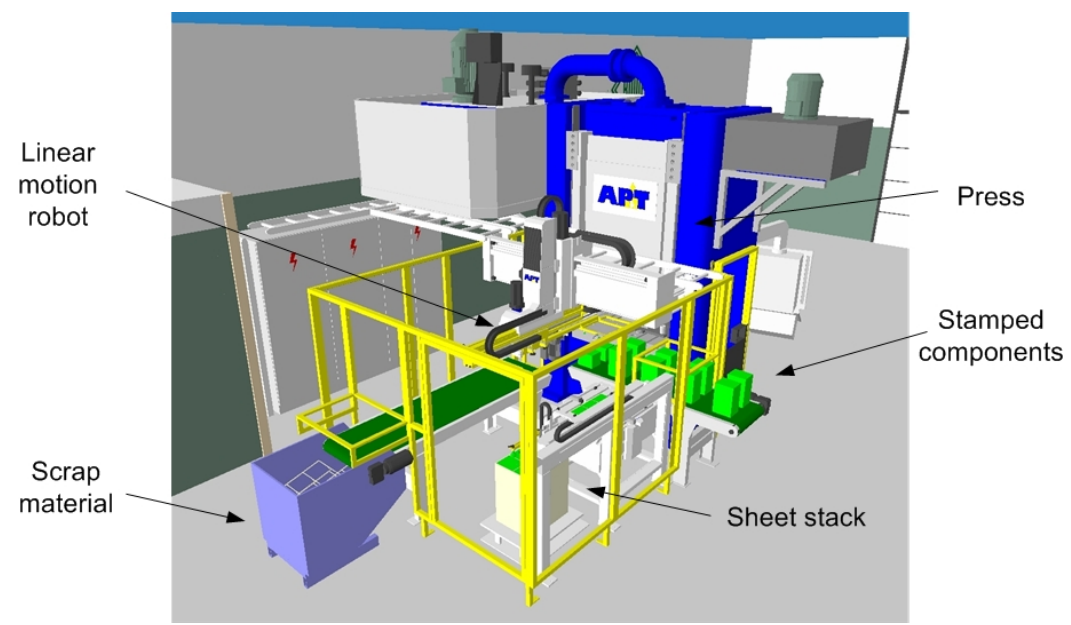

[insert about here:] Figure 2: Animation snapshot from CAR.

\subsection{Co-simulation across PPR Domains}

Co-simulation is the integrated use of different types of simulation tools to solve a problem. One such example is the use of condensed FE models in MBS simulation as discussed above. Whilst co-simulation across PPR domains has a large potential as a support for concurrent engineering, examples of co-simulation across different PPR domains are still scarce. One example is the integration of a process model into a CAR tool as developed by DELFOi for the simulation of a robot assisted press brake (with the robot supporting the product during bending) [34]. Another example is the integration of sensor simulation with CAR [35]. This application is used for process in the loop simulation of sheet metal welding with actual sensor data, i.e. the sensor data of the welding process is input for the simulation model which in turn is connected to the robot controller. This allows for a tight integration between physical world and virtual world, and is used for seam tracking and obstacle avoidance. An additional 
advantage is that the simulation model can "look ahead" which helps to avoid robot poses that represent (or are near) singular points.

\section{ADVANCED USE OF RESOURCE SIMULATION FOR MACHINE SYSTEM DEVELOPMENT}

The VIR-ENG project $[36,37]$ has highlighted the potential role of virtual engineering in machine system design. Whilst VIR-ENG itself focused on machine system development, it also forms the basis for the simulation based machine service support system discussed later on in this paper. The main objective of the project was to develop highly integrated design, simulation and distributed control environments for building agile modular manufacturing machine systems which offer the inherent capacity to allow rapid response to for instance product model changes. In the project, a component based paradigm was adopted for both hardware and software development. In essence, machine systems including their control system are developed in a virtual environment and subsequently implemented as a physical system. Software tools, solutions and technologies used in VIR-ENG include the simulations tools QUEST (DES) and IGRIP (CAR). Furthermore, OLE for Process Control (OPC) has been used. OPC is an open interoperability industrial standard for sharing manufacturing information in an enterprise-wide manner. It is based on the Microsoft technologies of OLE (Object Linking and Embedding), COM (Component Object Model) and DCOM (Distributed Component Object Model). It provides “plug-n-play” connectivity and interoperability between disparate automation devices, systems and software, from the shop floor to enterprise wide systems. In VIR-ENG, the IEC 1131-3 standard was adopted. 
The main environments developed in the VIR-ENG project are the highly integrated Modular Machine Design Environment (MMDE), Control System Design Environment (CSDE) and Distributed Run-time Environment (DRE). An Infrastructure and Integration Services (IIS) environment based on the component object-based computing platform provides all the "pipes and plumbing” for the information integration within the VIR-ENG environment. The integration services are applied not only to the VIR-ENG environment but also support enterprise wide information integration. These environments and their relationships are shown in Figure 3.

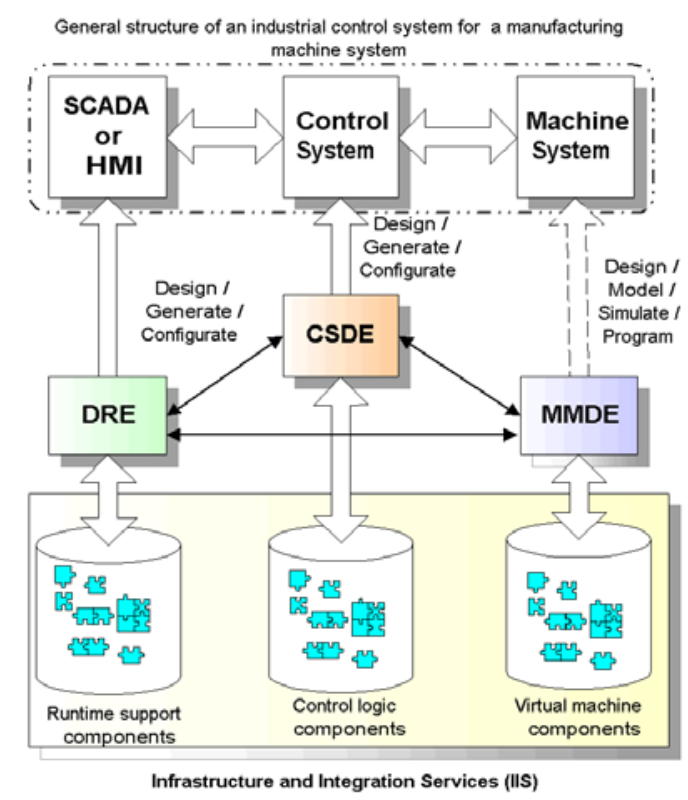

[insert about here:] Figure 3: VIR-ENG environments and their relationships

\section{SIMULATION-BASED SERVICE AND MAINTENANCE}

\subsection{The Industrial Problem of Delivering Service \& Maintenance at Remote}

\section{Locations}

Service and maintenance is an intricate specialist task and machine builders often have to provide service at short notice. Often, machine systems are installed at 
remote locations and the machine builders have to sign rigorous service contracts as part of the sale agreement. Increasingly, machine systems are part of a lease agreement through which OEMs lease production capacity instead of the equipment itself, which puts even more pressure on machine builders to provide adequate service \& maintenance. Machine builders would benefit enormously from extended possibilities to monitor and diagnose equipment operating at distant locations - both for conditionbased preventive maintenance and for diagnostic purposes before flying in qualified maintenance personnel and spare parts. Even within a single plant, the possibility to monitor manufacturing equipment from a central service and maintenance office has obvious benefits. Most condition monitoring applications in manufacturing are limited to sensor information fusion for applications such as tool-wear monitoring [38] or spindle bearing monitoring [39]. Examples of sensor information are vibrations and oil contamination [40], temperatures and electric currents. Whilst this approach in itself is useful for preventive service and maintenance, it is limited to some features of individual machines rather than being applicable to machines as part of a machine system. In the past, cyclically or sporadically occurring faults, which could not be identified automatically and monitored directly by fault messages of the controllers, had to be detected by visual observation [41]. In the era of globalisation, this is not desirable if the service and maintenance support has to be provided continuously on a worldwide basis. It is also not applicable to machine failures for which the error symptoms could not be repeated for observation. Video diagnosis systems and corresponding fast offline video transmission technologies can be seen as an enhancement to provide visual information to improve the analysis capability [42]. However, this incorporates high additional cost in installing and running the video systems; transferring the video data over the network is also very costly in terms of the bandwidth requirements and 
network traffic. Furthermore, monitoring by video can only be applied to observe a very limited number of perspectives of an individual machine so that it falls short of the applicability for monitoring the complex machine system as a whole, where faults may occur with different components at different locations. Because of these reasons, the idea of using three-dimensional (3-D) graphical visualisation models has been proposed by many researchers, largely based on VRML and Java. Such 3-D models are very useful in providing users with highly visualised and easily comprehensible information. They provide users with increased flexibility and functions such as walkthrough and fly around that are impossible by using stationary video cameras [43]. Nevertheless, the disadvantage of using VRML or Java is that it requires significant efforts of the users to devise and then codify the kinematics models for the machines being monitored, which is often not justified in an industrial context, especially if the models are built only for some specific purposes.

It has been noted that the advanced kinematics modelling and realistic animation features that are nowadays commonly supported by many advanced virtual engineering systems have offered a highly promising alternate solution to these visualisation models. The approach of extending virtual engineering tools is considered to be also highly cost-effective if the same set of simulation models, developed incrementally during the machine design and development lifecycle, can be continuously reused. Previous research conducted in the ESPRIT project VIR-ENG [36, 44] has proposed and successfully demonstrated the use of virtual engineering to support the entire development lifecycle of modular manufacturing machine systems, from conceptual design during negotiation and quotation stage, to the final machine commissioning phase. It has been envisaged that the graphical simulation models developed incrementally during the machine development stage can be effectively applied to the 
operational monitoring and maintenance phase as well. In addition to the modelling capability and validity of the simulation models, the applicability and effectiveness of such an approach rely also heavily on a framework that tightly integrates virtual engineering tools (machine system simulations) with a set of Internet-based reconfigurable modular maintenance supporting tools.

\subsection{The Design of a Simulation-Based Service \& Maintenance Support System}

In the MASSIVE project at the authors' laboratory, a simulation supported machine service support system (MSSS, Figure 4) has been designed and implemented. The system consists of on-site components, mainly for data acquisition (shown to the left) and components at the service provider site. The latter consist of components for data communication, storage and processing, components for analysis, and a user interface.

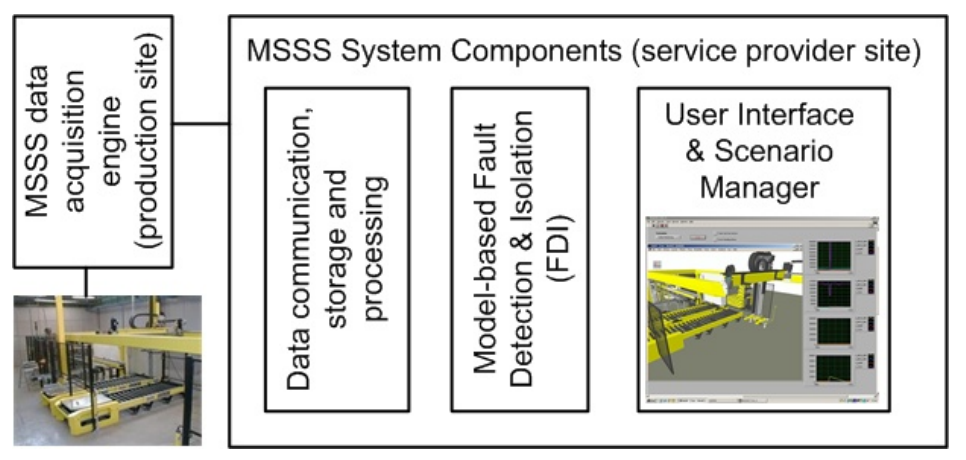

[insert about here:] Figure 4: MSSS main component groups

The approach taken in the project builds upon the tools and techniques from the VIR-ENG project and is an extended part of the machine system design and control environments from VIR-ENG. A key element in this approach is the seamless integration between simulation model (which is a hybrid DES/CAR model although 
CAR prevails) and physical equipment. This integration makes it possible for instance to:

- Study failure modes and their effects during machine system design through simulations in which certain disturbances/faults are emulated.

- Monitor the operation of the machinery system on-line, which facilitates both supervision by humans and data-acquisition.

- In the case of breakdowns, retrieve control code execution, sensor information from a temporal database and carry out a "replay” of the machinery system’s recent history in the simulation model.

- Develop, test and upload temporary control code in the case of temporary reconfiguration due to machine service activities (this is a functionality inherited from VIR-ENG).

The kernel of MSSS is essentially a remote data acquisition and analysis system. An advanced data acquisition, pre-processing and management framework is the foundation for all other functions. The data acquisition system can be remotely configured so that specified parameters, machine process variables and signals can be acquired in prescribed time intervals and sampling rates. Configurations for routine periodic data logging can also be selected for day-to-day monitoring. Configuration of the data acquisition components is enabled through XML Web services using the user interface functions provided by the Scenario Manager.

MSSS offers continuous visual monitoring, but in the case of a machine failure (breakdown), MSSS users can also use the historical data saved in the database to carry out a "replay" to investigate the recent history of the machine system and current status using the corresponding simulation models. In these cases, animations are driven by the historical data acquired. Simultaneously, the reference process models are used to 
generate the nominal dynamic response of the system with the input data from the historical data. The output data generated by the simulator and from the collected historical data can be visualised and compared using various data analysis and residual analysis techniques. The data visualisation features enhance the 3D animation by presenting useful “non-animated” data like electric current and voltage produced both from the simulator and the collected data as an additional means for assisting any monitoring and diagnostic tasks.

Fault alarms can be generated by the diagnostic agents, for instance, if a residual signal is evaluated to exceed a certain threshold; but projected more advanced fault detection algorithms can easily be incorporated into MSSS.

The remote monitoring function in combination with the replay function is very useful in a number of situations, in particular when the manufacturing system is installed at a remote location and the machine builder needs to know which type of service specialist needs to be flown in or which spare parts need to be sent to the site. When an error occurs occasionally, seemingly without a pattern, it can be difficult to decide what causes the error. With the use of MSSS, the pattern can be unravelled by running replays using media functions such as "slow motion" "rewind" and "fast forward” and using the scenario manager to select data signals of particular interest. In this way, "situation awareness" about the machine system's condition and the errors can be obtained.

\section{IMPLEMENTATION OF MSSS FOR PRESS LINES AND CELLS}

\subsection{The Service \& Maintenance Problem for Press Lines and Cells}

Whilst remote monitoring and diagnostics provide benefits to the machine system builder as well as to the machine system user in almost any kind of 
manufacturing activity, sheet metal transfer press lines form an application in which these benefits are particularly large. In machining, a machine breakdown poses problems in itself but operations can often continue with a slightly lower output through re-scheduling, re-allocation of machining operations or other solutions. In sheet metal transfer press lines, the situation is radically different. If one single station in a transfer press line fails, in principle the whole line comes to a standstill. When buffers are available, perhaps some production may continue, but only to a very limited extent. Even SMED (Single Minute Exchange of Dies) technology can not remedy the situation to the same extent as in for instance car engine machining.

Whilst failure of a machine or peripheral equipment is particularly problematic for multi-press lines, it also poses severe problems for single-press cells. Such cells are often designed for a specific part or part family; other parts can only be accommodated if the peripheral equipment is suited to handle these parts and if the factory layout permits this. Likewise, if the cell has a breakdown, production can only be moved to other cells if these are available at all (this is often not the case; the cell may be the only press cell in the plant, or other cells may not be available due to planning/scheduling restrictions) and can technically accommodate the same parts.

\subsection{The Industrial Case at AP\&T}

Currently, two industrially-based test-beds have been used for the demonstration and testing of MSSS. The first test-bed, a prototype implementation, consists of an industrial assembly cell (valves in a cylinder head) that is located at Euromaint Industry (formerly Euromation) and that can be monitored remotely (in this case, at the University of Skövde) via an internet connection. This connection is bi-directional; control code can be uploaded, parameters set, and the cell can be stopped from the 
remote location in the case of an emerging problem. The fully industrial test case consists of a press cell produced by AP\&T located in Blidsberg, Sweden and installed at one of their customers in Denmark. In this test-bed, the press and peripheral equipment such as de-stacker, conveyors and handling robot are used to test the motion playback and diagnostic capability of MSSS. Testing revealed that the resolution of the internal clock in the simulation software is not adequate for monitoring and diagnostics purposes. This problem can be solved by adding a clock with a higher resolution as a "dummy device" in the simulation model. The implementation of this solution and the subsequent "tuning" of the signal sampling intervals are discussed in more detail in [45].

The type of press cells and multi-press lines that AP\&T sells world-wide is fully automatic with a high grade of complexity. Since their main service support team is situated at their headquarter in Blidsberg, where most of the lines are designed and built, the remote service and support functions of MSSS can play a significant role for providing satisfactory services to their distant customers. With MSSS, the service support personnel at the head office can conduct a discussion about what and where the problem within the press line/cell is situated with the customer or the technician on-site through the MSSS “motion playback” function. Motion playback allows the simultaneously running of a 3D virtual machine together with data plotting from control signals data that are saved in the database. The option to run the simulation and data plotting of all important control signals at the same time in a slower pace than real time with multiple repetitions would give much greater opportunities for expert personnel to identify, for example, cyclically or sporadically occurring faults or synchronisation errors in signal exchanges between robotic devices and press machine in the press cell.

Figure 5 illustrates the scenario on how MSSS can be used to detect a fault that occurs cyclically or sporadically by using the real data gathered on-line from a press cell 
in AP\&T. As indicated in the Gantry GX5-Axis X-Position data plot (the small window to the left), there is a jerky movement of the axis, resulting in an overshoot of the axis.

Such kind of faults may be due to component wear or another fault but it is very difficult to observe these when they occur sporadically or do not have directly observable consequences such as affecting the quality of the product. However, the fault may eventually result in a machine breakdown or may cause damage when another product is processed in the cell. By using the model-based fault-detection algorithm that applies to the monitoring of the position (see Gantry GX-5-Axis X-Position data plot on the left small window), the exception can then be detected automatically and the operator is informed through a fault message; in this case that the X-Position exceeds the predicted value by more than $10 \%$.. A service engineer can then use the playback animation to identify accurately what the fault is and where and when it occurred; subsequently, appropriate action can be taken or suggested. In the scenario shown in Figure 5, the service engineer can compare the axis movements with the torque curve shown in the small window at the centre to analyse if there is a corresponding abnormal behaviour in the torque curve. 


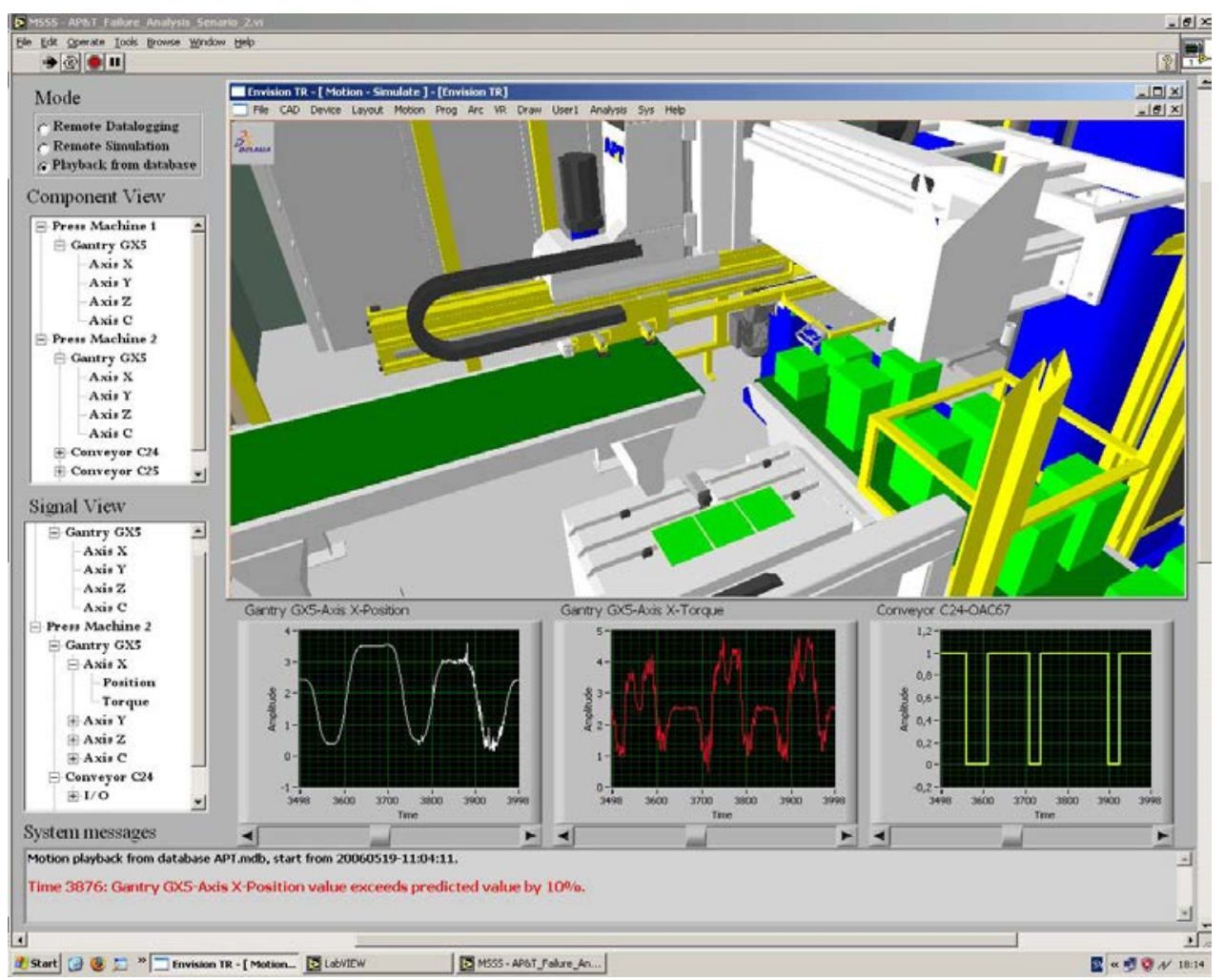

[insert about here:] Figure 5: Online monitoring of I/O signal and motions of a press cell.

Figure 6 illustrates another scenario that the MSSS data plot can be used for, namely to detect a synchronisation error between I/O signals. For example, it is intended that the rising edge of the I/O signal from the sensor on the conveyor (yellow "block type” signal) will trigger the change in X-Position of the gantry robot at about time 400 in the plot. However, as indicated in the overlaid data plot, the change in the $\mathrm{X}$-axis position is actually triggered by the falling edge; such an error might not be easily identified during the programming stage but may produce a problem that affects the quality of products or that may even be hazardous to the machine components. Such kind of synchronisation issues require specific attention when using simulation models 
for MSSS purposes; this as opposed to using these models for off-line programming (OLP) where these requirements are more relaxed [4]. This also highlights an important aspect of verification \& validation, namely that verification \& validation is always done against the background of a specific purpose. Models that are correct and valid for one purpose may not be suitable for another purpose (actually, using a model for a purpose for which it was not intended without carrying out a renewed verification \& validation process is one of the pitfalls in VM).

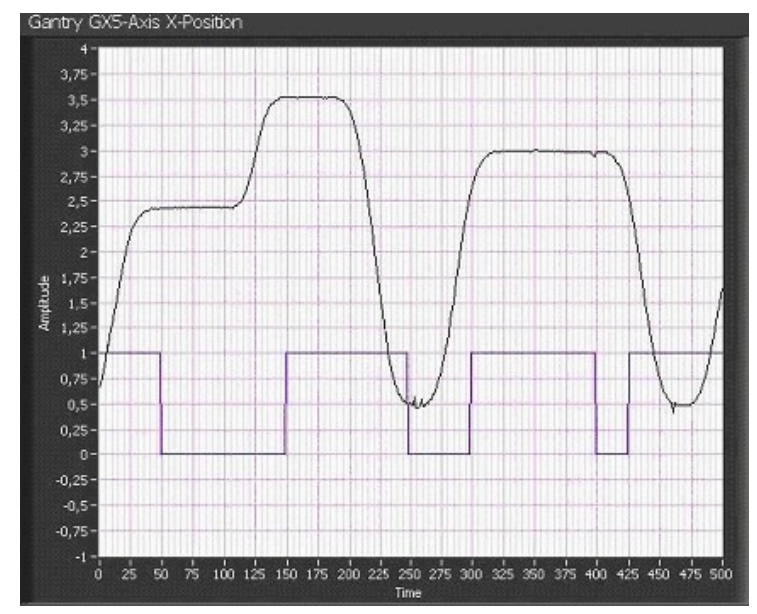

[insert about here:] Figure 6: Overlaid data plot to identify I/O signal synchronisation error (colours inverted for better clarity).

MSSS also allows users to perform queries on the database for searching specific extreme values. This feature is of enormous value when trying to identify errors that seemingly occur stochastically, but it must be used carefully as otherwise, abundant data would be logged repeatedly. Therefore, the possibility for users to configure the data logging of MSSS remotely over the internet is a crucial function for AP\&T's expert personnel who are searching for, or performing analysis on, peak values as well as specifying different types of fault-localizing scenarios. The ability to specify what 
data is to be logged over the Internet becomes exceptionally important when the complexity and size of the manufacturing system increase.

Based on all these advantages that MSSS can bring along, AP\&T is considering the possibility of including MSSS as an add-on service for their multi-press line machine control systems. This will facilitate them to provide better and quicker services to their customers, in terms of remotely diagnosing problems and testing solutions without having to send specialist staff to the site in question. Furthermore, if parts need to be replaced, spare parts can be sent to the site straight away. This saves time and in many cases, the replacement can be handled by local maintenance personnel. An additional advantage of MSSS as reported by AP\&T is that by keeping the simulation model "alive", it also serves as documentation for customer support functions.

\section{MSSS IN AN INFORMATION FUSION PERSPECTIVE}

Information Fusion (IF) encompasses the theory, techniques, and tools conceived and employed for exploiting the synergy in the information acquired from multiple sources (sensors, databases, information gathered by human, etc.) such that the resulting decision or action is in some sense better (qualitatively or quantitatively, in terms of accuracy, robustness, etc.) than would be possible if these sources were used individually without such synergy exploitation [46]. An example of a (military specific) model for IF is the JDL ("Joint Directors of Laboratories") model [47] that describes the stepwise refinement of information. Another military specific model is the OODA loop [48], where OODA stands for “Observe, Orient, Decide and Act”. A more generic model, not addressing the details of the IF process itself but showing its interactions with databases, external processes and simulations is shown in Figure 7. This model is used within the research program "Information Fusion from Databases, Sensors and 
Simulations”, a major research initiative at the University of Skövde that aims at the development of generic IF theory, tools, methods and infrastructures [49]. Application scenarios include manufacturing [50, 51], retail sector, bioinformatics, defence, emergencies management, and precision agriculture.

Whilst this model describes some of the principle interactions in MSSS, MSSS also has some application specific features that form an extension of the generic model. For instance, the (active) database in MSSS can generate alarms that are propagated to decision level (the highest level within the information fusion process). A major extension is formed by the way MSSS connects the real process and the simulation environment. This connection creates a mixed real/virtual environment, something that is also known as a "synthetic environment”. There is some parallel with a Turing Test: A (trainee) service engineer would not be able to distinguish whether (s)he is looking at a visualisation that is driven by the real process or one driven by the simulation engine, or even by a mix of these. The MSSS specific extensions to the generic IF model are shown in Figure 8.



[insert about here:] Figure 7: Generic model for external interactions of IF. 


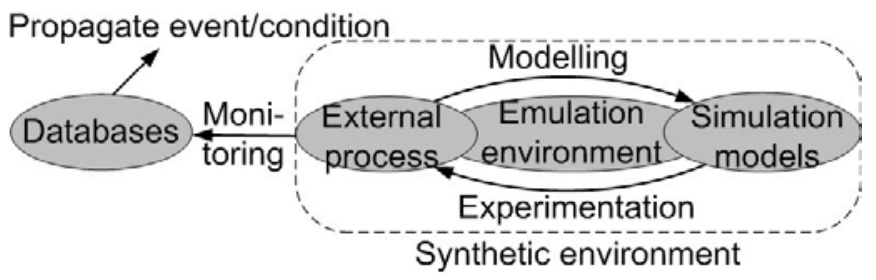

[insert about here:] Figure 8: MSSS specific extensions to the generic model.

At the current stage of development, MSSS provides an example of IF for human decision support; it presents the information in such a way that the service \& maintenance experts can develop "situation awareness" about the press line without the need to visit the physical system on-site. This situation awareness provides the basis for human decision making. However, when more advanced features for diagnostics are incorporated in MSSS, some decisions may be made automatically or semiautomatically.

\section{CONCLUSIONS AND FURTURE WORK}

A machine service support system (MSSS) has been designed and implemented. The system is an example of advanced use of 3-D graphical simulation tools in the resource domain. It extends the use of simulation models from the machine system design and development phase into the operational phase. This, however, requires special attention for the synchronisation of the simulation and the various signals.

MSSS can be used for continuous online monitoring or for analysis of previous operation with the use of media player functions. In the latter case, the user can remotely configure the data logging to avoid logging of redundant data.

Whilst MSSS may be beneficial to almost any system integrator or machine builder installing equipment at remote locations, suppliers of press lines and press cells 
can benefit in particular as a problem with any device in such lines or cells may hamper the operation seriously and not seldom result in a complete production stop. As a result, after successfully testing MSSS in a fully industrial pilot implementation, one of the project partners is considering to make MSSS available to their customers as an add-on for their press lines and cells.

MSSS in a broader context is an example of a synthetic environment that is used to create an enhanced "situation awareness" for human decision support in an information fusion context.

An area for future research on MSSS is the design and implementation of more advanced functions for diagnostics and fault detection algorithms that may allow some decisions to be taken by the system automatically but also will support the human decision maker with better information in general.

\section{Acknowledgements}

This work has been developed in partnership with the Knowledge Foundation, Sweden, under Knowledge Foundation grants to MASSIVE and to the Information Fusion Research Program. The authors gratefully acknowledge the contributions of the industrial partners in the MASSIVE project: AP\&T, DELFOi, Euromaint Industry, Volvo Powertrain Skövde, and Volvocars Engine Skövde.

\section{REFERENCES}

1. L.J. De Vin, A.H.C. Ng, J. Oscarsson, Simulation Based Decision Support for Manufacturing System Life Cycle Management, Journal of Advanced Manufacturing Systems 3(2) (2004) 115-128 
2. S.J. Steiner, A. de Vicq, A.J. Medland, ARMMS - Agility and ReConfigurability - Drivers, Approaches and Classification Methods, WMC 2001, Rochester, NY, 2002

3. P. Iskanius, An Agile Supply Chain for a Project-oriented Steel Product Network, PhD Thesis, University of Oulu, Finland, 2006

4. L. Petterson, Real time cell monitoring and machine diagnostics via geometric simulation software, MSc Thesis, University of Skövde / Loughborough University, 2006

5. L.J. De Vin, P.R. Moore, J. Pu, A.H.C. Ng, S. Steiner, A. De Vicq, A.J. Medland, ARMMS - A Review of Approaches to Agile Manufacturing, IMC-19 Conference, Queen's University, Belfast, UK, 2002, pp. 3-11

6. U. Eriksson, Diffusion of Discrete Event Simulation in Swedish Industry, PhD Thesis, Chalmers University of Technology, Sweden, 2005

7. P. Solding, P. Eriksson, L.J. De Vin, Discrete Event Simulation in Operational Production Planning - An Outline, IMC-20 Conference, Cork Institute of Technology, Cork, Ireland, 2003, pp. 181-187

8. A. Ingemansson, J. Oscarsson, Simulation and Production Improvement Techniques, $39^{\text {th }}$ CIRP International Seminar on Manufacturing Systems, Bled, Slovenia, 2006

9. M. Sundberg, A.H.C. Ng, J. Adolfsson, L.J. De Vin, Simulation Supported Service and Maintenance in Manufacturing, Proceedings IMC-23, University of Ulster at Jordanstown, UK, 2006, pp. 559-566

10. R. Klar, Extended discrete event simulation including restriction criteria for material flow analysis, MSc Thesis, University of Skövde, 2002 
11. D. Brade, A Generalized Process for the Verification and Validation of Models and Simulation Results. Dissertation, Fakultät für Informatik, Universität der Formatted: English (U.S.) Bundeswehr München, Germany, 2004. Also available at http://137.193.200.177/ediss/brade-dirk/meta.html (accessed 07/07/2007)

12. PROSPEC, THALES JP11.20 Report JP1120-WE5200-D5201-PROSPECV1.3, 2004. Also available at http://www.vva.foi.se (accessed 07/07/2007)

13. L.J. De Vin, H. Lagerström, D. Brade, Verification, Validation and Accreditation for Manufacturing Simulation, FAIM 2006, University of Limerick, Ireland, 2006, pp. 327-334

14. NSF, Simulation-Based Engineering Science, 2006. Also available at http://www.nsf.gov/pubs/reports/sbes_final_report.pdf (accessed 07/07/2007)

15. L.J. De Vin, G. Sohlenius, The Role of Simulation in Innovative Industrial Processes, IMC-23, University of Ulster at Jordanstown UK, 2006, pp. 527-534

16. A.J. Morris, R. Vignjevic, Consistent finite element structural analysis and error control, Computer Methods in Applied Mechanical Engineering 140 (1997) 87108

17. U. Sellgren, Component Mode Synthesis - A method for efficient dynamic simulation of complex technical systems. Technical Report, Royal Institute of Technology (KTH), Stockholm, Sweden, 2002

18. P. Vreede, A finite element method for simulation of 3-dimensional sheet metal forming. PhD Thesis, University of Twente, The Netherlands, 1992

19. D. Wiklund, Tribology of Stamping - The Influence of Designed Steel Sheet Surface Topography on Friction, PhD Thesis, Chalmers University of Technology, Sweden, 2006 
20. L.J. De Vin, Air Bending of Sheet Metal, FAIM 2005, Deusto University, Bilbao, Spain, 2005, pp. 465-473

21. J.R. Duflou, J. Váncza, R. Aerens, Computer aided process planning for sheet metal bending: A state of the art, Computers in Industry 56 (2005) 747-771

22. DELEM (CNC controllers for sheet metal machines), Eindhoven, NL, 2006

23. E. Atzema, Formability of Sheet Metal and Sandwich Laminates. PhD Thesis, University of Twente, The Netherlands, 1994

24. W. Klingenberg, U.P. Singh, W. Urquhart, A Finite Element Aided Sensitivity Analysis of the Free Bending of a Drawing Quality Steel, Proceedings of the 2nd International Conference on Sheet Metal, University of Ulster at Jordanstown, UK, 1994, pp 41-48.

25. L.J. De Vin, A.H. Streppel, U.P. Singh, H.J.J. Kals, A Process Model for Air Bending, Jrnl of Materials Processing Technology 57(1-2) (1996) 48-54.

26. D. Lutters, A.H. Streppel, J. Huétink, H.J.J. Kals, A process simulation for air bending, in: Proceedings of the 3rd International Conference on Sheet Metal, University of Central England, Birmingham, UK, 1995, pp. 145-154.

27. D. Lutters, A.H. Streppel, H.J.J. Kals, Adaptive press brake control in air bending, in: Proceedings of the 5th International Conference on Sheet Metal, University of Ulster at Jordanstown, UK, 1997, pp. 471-480.

28. L.J. De Vin, U.P. Singh, Adaptive Control of Mechanical Processes:

Brakeforming of Metal Sheet as an Example, Mechatronics98, University of Skövde, Sweden, 1998, pp 141-146.

29. W. Klingenberg, U. P. Singh, Further observations and review of numerical simulations of sheet metal punching, International Journal of Advanced Manufacturing Technology 30 (2006) 638-644 
30. U.P. Singh, S.K. Maiti, P.P. Date, K. Narasimhan, Numerical Simulation of the Influence of Air Bending Tool Geometry on Product Quality, Proceedings SheMet 2000, University of Central England, Birmingham UK, 2000, pp. 477488

31. U.P. Singh, W. Urquhart, P.P. Miller, Finite element simulation of cutting performance of CNC punches, Proceedings SheMet 1992, University of Central England, Birmingham UK, 1992, pp. 125-140

32. M. Urenda Moris, L.J. De Vin, P. Eriksson, Introducing discrete event simulation for decision support in the Swedish health care system, In Proceedings of the 2004 Western MultiConference: Health Sciences Simulation 2004 (Eds. Anderson J.G. and Katzper M.), San Diego CA:SCS-Society for Modeling and Simulation International, San Diego, CA., 2004, pp. 48-53

33. G. Bäckstrand, D. Högberg, L.J. De Vin, K. Case, P. Piamonte, Ergonomics Analysis In A Virtual Environment, Proc of IMC-23, University of Ulster at Jordanstown, UK, 2006, pp. 543-550

34. C. Tistrand, P. Bodin, Development of simulation / offline programming for robot-assisted press brakes (in Swedish), BSc Project, University of Skövde, Sweden, 2001

35. M. Olsson, Simulation and execution of autonomous robot systems. PhD Thesis, Lund University, Sweden, 2002

36. J. Adolfsson, A.H.C. Ng, P.R. Moore, Modular Machine System Design Using Graphical Simulation, 33rd CIRP International Seminar on Manufacturing Systems, Royal Institute of Technology (KTH), Stockholm, Sweden, 2000, pp. $335-340$. 
37. P. Olofsgård, A.H.C. Ng, P.R. Moore, J. Pu, C.B. Wong, L.J. De Vin, Distributed Virtual Manufacturing for Development of Modular Machine Systems, Journal of Advanced Manufacturing Systems 1(2) (2002) 141-158

38. B.V. Dasarathy, Information Fusion as a Tool in Condition Monitoring, Information Fusion 4 (2003) 71-73.

39. S.M.E. Salvan, R.M. Parkin, J. Coy, M.R. Jackson, W. Li, Condition Monitoring and Location of Multiple Roller Bearings Using Three Sensors, Mechatronics 2002, University of Twente, NL, 2002, pp. 998-1007.

40. M.C. Carnero, Selection of diagnostic techniques and instrumentation in a predictive maintenance program. A case study. Decision Support Systems 33(4), (2005) 539-555.

41. F. Groll, Process visualization and optimization with modern software tools. In Proceedings of the International Symposium on Robotics, 7-11 October, Royal Institute of Technology (KTH), Stockholm, Sweden, 2002, pp. 193-197.

42. A. Wolfram, R. Isermann, Component based tele-diagnosis approach to a textile machine, Control Engineering Practice 10 (2002) 1251-1257.

43. L. Wang, P. Orban, A. Cunningham, S. Lang, Remote real-time CNC machining for web-based manufacturing, Robotics and Computer-Integrated Manufacturing 20(6) (2004) 471-601.

44. P.R. Moore, J. Pu, A.H.C. Ng, C.B. Wong, S.K. Chong, J.K. Adolfsson, P. Olofsgård, J.O. Lundgren, Virtual Engineering: An integrated approach to agile manufacturing machinery design and control, Journal of Mechatronics 13 (2003) 1105-1121. 
45. L. Pettersson, J. Adolfsson, A.H.C. Ng, L.J. De Vin, Cell Monitoring and Diagnostics Using Computer Aided Robotics, 40 ${ }^{\text {th }}$ CIRP International Seminar on Manufacturing Systems, Liverpool (UK), 2007

46. B.V. Dasarathy, Information Fusion - What, Where, Why, When, and How?, Information Fusion 2 (2001) 75-76.

47. L. Llinas, C. Bowman, G. Rogova, A. Steinberg, E. Waltz, F. White, Revisiting the JDL Data Fusion Model II. Fusion2004, Swedish Defence Research Agency (FOI), Stockholm, Sweden, 2004, pp. 1218-1230.

48. H. Warston, H. Persson, Ground surveillance and fusion of ground target sensor data in a network based defense. Fusion2004, Swedish Defence Research Agency, Stockholm, Sweden, 2004, pp. 1195-1201.

49. S.F. Andler, L. Niklasson, B. Olsson, A. Persson, T. Planstedt, L.J. De Vin, B. Wangler, T. Ziemke, Information Fusion from Databases, Sensors and Simulations: A collaborative Research Program. 29th Annual NASA/IEEE Software Engineering Workshop (SEW-29), IEEE Computer Society Press, 2005

50. L.J. De Vin, S.F. Andler, A.H.C. Ng, P.R. Moore, J. Pu, B.C.B. Wong, Information Fusion: What can the Manufacturing Sector Learn from the Defence Industry?. IMC-22, University of Tallaght, Ireland, 2005, pp. 363-371.

51. L.J. De Vin, A.H.C. Ng, J. Oscarsson, S.F. Andler, Information Fusion for Simulation Based Decision Support in Manufacturing, Robotics and Computer Integrated Manufacture 22 (2006) 429-436 


\section{List of figures:}

Figure 1: Relationships between System of Interest and Model [12]

Figure 2: Animation snapshot from CAR.

Figure 3: VIR-ENG environments and their relationships

Figure 4: MSSS main component groups

Figure 5: Online monitoring of I/O signal and motions of a press cell

Figure 6: Overlaid data plot to identify I/O signal synchronisation error (colours inverted for better clarity).

Figure 7: Generic model for external interactions of IF.

Figure 8: MSSS specific extensions to the generic model. 